\title{
EFFICIENCY OF CREATIVE MOBILE APPLICATION TO PROMOTE TOURISM: CASE OF BANG NAM PHEUNG MARKET, SAMUT PARKAN PROVINCE
}

\author{
${ }^{1}$ Kittikhun Meethongjan; ${ }^{2}$ Somsak Klaysung \\ ${ }^{1}$ Suan Sunandha Rajabhat University, Thailand. Email: kittikhun.me@ssru.ac.th
}

\begin{abstract}
The extensive usage of smart phones and digital applications has changed the lifestyle, this trend has also affected tourism, it has transformed the tourism industry ways to access visitors during travelling. Mobile applications are used for different purpose in tourism from booking, mapping, finding locations and payments. Mobile application usage is very common in Thailand. Though, the drivers behind increased use of such applications in hospitality enterprises and markets in Samut Parkan province is still unidentified and imprecise. On the basis of Theory of Acceptance this paper is targeted to identify the factors that drives tourist's continuous intention to use mobile application. A purposive sampling was instigated in restaurants, food stalls, souvenirs shops in Bang Nam Pheung Market, compiling 415 useful survey responses to check that how different drivers such as personal innovation, awareness and destination infrastructure risk impact continuous intention to use mobile application. This study also examined the moderation effect of information knowledge on interconnection among Mobile applications drivers and tourist intention to uses the mobile applications. This study is offering several helpful points and recommendations for tourism organizations and government to effectively incorporate mobile application. Mobile application developers can also refer to this paper.
\end{abstract}

\section{Keyword:}

Creative Mobile Application, Intention to use Mobile Application, Personal Innovation, Awareness, Destination Infrastructure Risk, IT Knowledge, Tourism, Thailand.

Article Received: 18 October 2020, Revised: 3 November 2020, Accepted: 24 December 2020

\footnotetext{
${ }^{1}$ Suan Sunandha Rajabhat University, Thailand. Email: kittikhun.me@ssru.ac.th
} 


\section{Introduction}

The basic purpose of this paper is to explore the natural beauty that lies in Bang Nam Phueng, Bangkok. This market place is unique as it comprises several shops of all varieties and every sort of element is available (Chuentako, 2019). The ancient culture, traditions, and value to the place with artistic styles and beauty impress every visitor. Bang Nam Phueng has a rich culture and temple. This study opens the doors of history and architecture style (Pongajarn, van der Duim, \& Peters, 2018). The market launched in 2004 and the market is visited mostly by the local community also the market deals with the basic needs of daily life such as foods and necessities.

The below enlists some common barriers of mobile application adoption intentions;

\section{Table 1: Common barriers to MA adoption intention}

\begin{tabular}{|ll|}
\hline Variables & Definition \\
\hline Risk barrier & $\begin{array}{l}\text { Resistance towards an innovation mainly due to the inconsistency } \\
\text { with present routine, plan, and exercise. }\end{array}$ \\
\hline Adoption intention & $\begin{array}{l}\text { Uncertainty concerning possible insignificant results of using an } \\
\text { application or service. }\end{array}$ \\
\hline & $\begin{array}{l}\text { Results and outcomes of the sum of the factors that peak into an } \\
\text { intention that indicates that the user is willing to execute specific } \\
\text { actions. }\end{array}$ \\
\hline
\end{tabular}

The use of the mobile application is considered as a significant factor that is presently contributing to the improvement of many businesses, specifically in growing the level of economy Christian, Pierce, Robson, and Schoudt (2016), a study recently by Desai (2016) evaluated the exclusive impact of mobile application in promoting business, the study also determines some effective factors regarding the continuous intentions to use mobile app. This indicates that much of the research has been conducted in the previous decades in terms of mobile application (MA) in improving business activities. Though the research has not been done regarding the tourism places of Samut Prakan province, thus the present effort is new as well as justified as the findings of this study help tourism experts in understanding the significance of MP in promoting tourism in Samut Prakan. Moreover, the below graph showing the usage and advantages of mobile applications in different aspects.

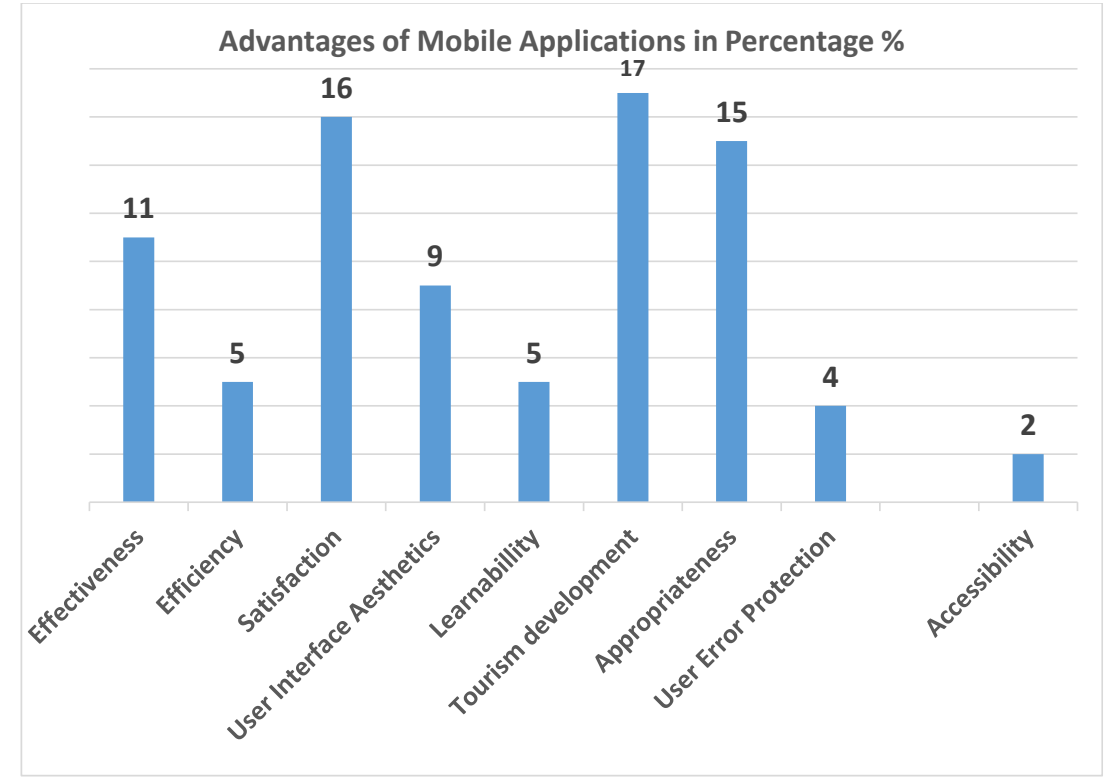


Based on the above just the current research effort has the following objectives, the major aim of the following research is to empirically explore the impacts of several support and information factors on the continuous intention to use MA in promoting the industry of tourism and tourism activities. This paper also has some other purpose like to investigate the overall impact of personal innovation, tourism place infrastructure risks, and awareness on the continuous intentions to use MA. Another major objective of the research is to analyze the mediating role of IT knowledge and information in improving the existing relationships between PI, DIR, and intentions to incorporate MA.

The current research paper significantly contributes to the forecasting of MA usage among different types of individuals by implementing and expanding the model of technology used to evaluate the critical factors and determinants of continuous usage of MA among individuals and tourists of Samut Prakan. The findings of the given paper prove to very helpful for the tourism sector and different tourism companies operate in Samut Prakan. The rest of the study is framed into a review of literature, research methodology, discussion about findings, and conclusion with implications.

\section{Literature review}

\section{Technology acceptance model (TAM)}

The TAM in an IT and communication systems theory that models how individuals and users come to accept and use a mobile application Scherer, Siddiq, and Tondeur (2019) the real system use is the final point where individuals want everyone to be able to do with MA, so the individual has to form a behavioral intention, which is according to $\mathrm{Wu}$ and Chen (2017) is a major factor that leads users individuals to use the application. The behavioral intentions are majorly influenced by personal innovation and attitude which is the general impression of the application and technology (Al-Emran, Mezhuyev, \& Kamaludin, 2018). The given model proposes that when users are presented with a new MA or technology several significant factors affect their intentions and decisions regarding how and when they will use it.

\section{The relationship between personal innovation and continuous intention to use a mobile application}

Personal innovation (PI) is initially about using the core principles of innovation and adapting them to one's personal and daily life Natarajan, Balasubramanian, and Kasilingam (2017) just as it for tourism businesses, a person's personal development indicates crests and troughs. According to Torous and Roberts (2017), there are stages when an individual is mainly driven towards learning as well as innovating current skills and properties or attributes and those are generally followed by phases where an impetus is required to move to the further phase of usage mainly because stagnation has set in Canbek and Mutlu (2016) and that imputes and intentional stimulation, comes in the shape of innovation. According to Palos-Sánchez, Saura, and ÁlvarezGarcía (2019), PI is the consent of tourists to adopt new technology, and this plays a favorable part in the usage of MA through modern channels and the desire to adopt it. Chao (2019)revealed that PI is a significant factor in evaluating the MA adoption consequences, therefore, based on the entire above discussion the present study hypothesizes that;

H1: Personal innovation has a significant impact on the rate of continuous intention to adopt MA.

\section{The correspondence between awareness and continuous intention to use a mobile application}

Mobile phones have a great impact on social life and psychological change in the behaviors of customers (Y. Wang, Wang, Wang, Wei, \& Wang, 2018). Tourism has now changed into an organized and evaluated activity and mobile phone apps or learning has revolutionized every field of life. Now it has become a compulsory element for every person to use apps for finding a place, product, map, or any aspect of life (Sezgin, Özkan-Yildirim, \& Yildirim, 2017). There must 
be a correspondence between awareness and continuous intentions to use these applications .mobile application helps in finding out the related places, responses to the questions, and also updates about the product and the services. According to Chaurasia, Verma, and Singh (2019)the need of developing awareness about the use and its benefits to make continuous use of mobile apps, the mobile applications help the tourist, the travelers, the visitors, even the simplest housewives. Mobile application helps in everyday matters to deal with and there must be continuous intentions to use mobile applications (Tarute, Nikou, \& Gatautis, 2017). Hence, the given research posits that awareness will improve the intention to use MA.

H2: Awareness has a significant influence on the continuous intention to use MA.

\section{The interrelation between destination infrastructure risk and continuous intention to use mobile app}

Infrastructure including ground, mobile signals, internet connection, and tourism services like rooms and rent plays a favorable role in travel and tourism competitiveness, mainly serving as the arteries of the sector, and from a worldwide perspective, infrastructure continues to develop (Carvajal-Trujillo, Molinillo, \& LiébanaCabanillas, 2020; Nzeribe, 2019; Ofino \& Orisadare, 2020; Ogunjimi, 2020; OkulichKazarin, Zhurba, Pagava, Kalko, \& Serbin, 2019). Destination infrastructure risk or DIR is mainly perceived as the risk linked to the flawing of the current internet infrastructure of the destination. According to Chen and Tsai (2019) if visitors or and users of mobile applications perceive the wireless connection of an NSP (network service provider) to be insignificant and unsafe, then they are insignificant likely to adopt it for tourism and another traveling purpose. Afolabi, Adeshola, Ozturen, and Ilkan (2020) founded that DIR has a direct impact on the degree of intention to adopt or use mobile application service for tourism purposes, and a recent effort by Mushwana and Maziriri (2017) indicates a significant relationship between DIR and the impulsion to adopt mobile app facility for better tourism results. Consequently, the present research posits that;

H3: Destination infrastructure risk has a significant influence on the continuous aim to adopt MA facilities.

The moderating impact of IT knowledge in the nexus between personal information and continuous intention to use MA

IT knowledge can refer to a theoretical as well as practical understanding of the IT field and according to Papa, Dezi, Gregori, Mueller, and Miglietta (2018) further IT knowledge is even what prevents an individual from making the same mistakes users made in the past. There can be no intention and action without IT knowledge, so IT information and background play a vital role in improving the extent of PI which further impacts the continuous intention to adopt MA (Mao, Liu, Zhang, \& Deng, 2016). According to Huang, Afsharifar, and Veen (2016) IT knowledge improves intention and thinking process of an individual because it helps to generate intentions in two ways, first IT knowledge helps to solve technology-related issues mainly by freeing up space in the working memory which directly influences the process of PI, and second IT information helps an individual circumvent intentions majorly by acting as a ready supply of things that affect the overall process of continuous intention (Ardito \& Petruzzelli, 2017). The technology acceptance model supports the moderating role of IT information because this model demonstrates that knowledge background is essential for continuous usage and adoption of modern technology without knowledge of technology there are no intentions. Therefore, based on the above discussion the current paper conjectures that;

H4: IT knowledge positively moderates the association between PI and continuous intention to use MP. 
The moderating role of IT information in the relationship between awareness and continuous intention to use MA

IT has a moderating role in building a relationship between awareness and continuous intention to use the mobile application because according to N. Wang, Sun, Shen, and Zhang (2018) IT is a crucial need for every part of life to move on, so to create awareness of its mobility and usage and also persuading in making continuous intentions to use this mobile application, MA has created kind of easy and accessible for everyone to cope with the problem, access to solutions and also to convey messages is the result of these mobile applications Pittino, Martínez, Chirico, and Galván (2018) so, IT has a lot of potential in persuading the customers all over the globe to use the mobile application and also the continuous intentions to make it a necessary element in everyday life, to say finally IT has a moderating role to relate the continuous use of the mobile application. Following the study, hence, hypothesizes that;

H5: IT information favorably moderates the nexus between awareness and continuous intention to use MA.
The moderating influence of IT knowledge in the interdependence between destination infrastructure risk and continuous intention to use MA

IT plays a very strong impact in the field of tourism as the destination infrastructure helps the tourist in managing their journey with the best possible structure and planning (Dzogbenuku, Amoako, \& Kumi, 2019). Mobile application helps in tackling the risks of the journey with the proper guidelines. The mobile apps of road maps, with complete information of areas, risks, advantages, and disadvantages all these are possible with the proper use of the mobile application. IT helps customers to use these applications with continuous intentions. Tourism is not just a simple tour and travel activity it is a properly organized system to motivate the customers to use the mobile application and also in the educational sector m_learning has a great impact (Jiang, Hu, Wang, \& Jiang, 2019). So to say IT knowledge relates a link between destination infrastructure risk and continuous use of MA. Therefore, this research effort suggests that;

H6: IT knowledge significantly moderates the relationship between DIR and continuous intention to use MA.

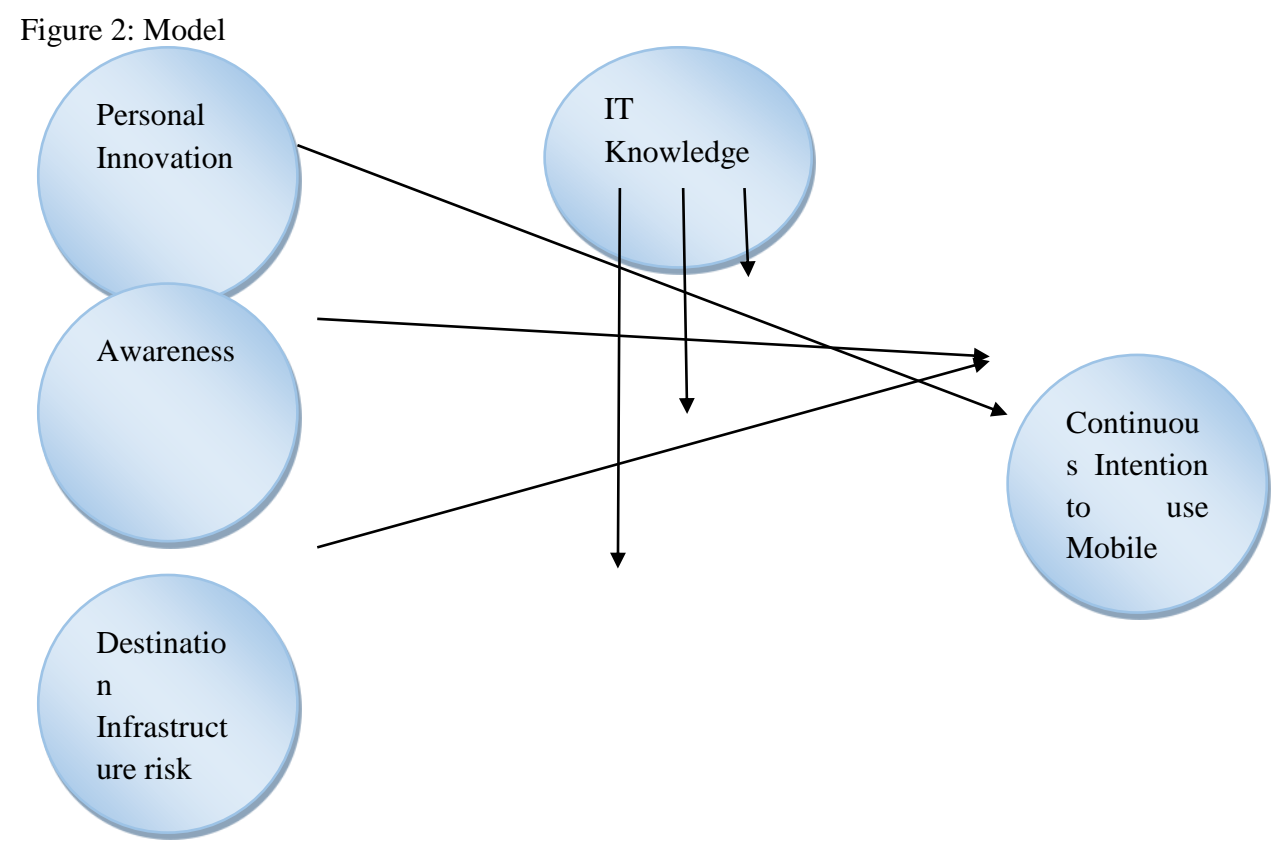




\section{Methodology}

\section{Study context and data collection}

The study was plotted in Samut Parkan province's famous Bang Nam Pheung Market that is a riverside market with variety of food, souvenirs and local products floating stalls which is very unique and is only common in Thailand. This area is not as much popular as other province but it adjoins Bangkok so on daily basis it has sufficient visitor that particularly come to explore this floating and unique market. A sample of 456 visitors was drawn from utilizing purposive sampling technique to collect data to achieve study objectives. The study is backed by positivism approach so it's a quantitative research and used a questionnaire survey to set off the research. The target of current paper were tourists, visitors and shoppers. The data was procured from the sample via self-reporting questionnaires. Data was collected by a team of surveyors hired at market and nearby hotels to gather questionnaires from respondents. The study was cross-sectional so data was collected in one time. Total 550 questionnaires were filled out of which 135 were plunged after screening due to lack of information and authenticity. At the end 415 valid responses were in hand for further analysis.

\section{Development of Research Instrument}

The data collection tool was a structured and selfreporting questionnaire that was designed to study different variable through relevant items and scale that have been already validated in many studios and supported by literature. We tried our best to design a questionnaire that was comprehensive and understandable for respondents. The questionnaire was reviewed before staring the original survey to remove chance of content invalidity and response bias. The total items were 18and for rating each item a five-point Likert scale was used.

For validation of personal innovation construct three items were drawn from Rogers (2003) study, these items measured how much respondent is ready to innovate and change by stating " I love to try new things before my peers and colleagues".
The results were intimating a high level of personal innovation with composite reliability of 0.927. Gerrard, Cunningham, and Devlin (2006) scale was exploited to develop items to measure awareness construct to see the level of awareness about mobile-apps. Three items including "I receive information about the benefits of M-apps" quantified respondent's awareness on five-point response scale which got 0.904 composite reliability. Three items were imitated from Dayour, Park, and Kimbu (2019) to estimate Destination-infrastructure risk that might influence tourist intention to use Mob-apps, one of the items as a sample is "Mobile Internet in this area may malfunction because of slow download speeds or network concerns". The respondent statements were recorded on Five-point Likert scale vacillating from $1=$ strongly disagree and $5=$ strongly agree and generated $\mathrm{CR}=0.932$.

For information knowledge Z. Wang and Wang (2012) scale was applied from which 6 measures were adapted to calculate IT knowledge of respondents. A sample item is "I have enough information and knowledge about using M-apps" responses were shown on 5-point scale and found to be highly reliable as per composite reliability was 0.927 .

Continuous intention to use mobile application was measured by three items that were grounded on the Venkatesh, Thong, and Xu (2012) scale, these items quantified the tourist intention to practice mobile applications such as "I will use additional M-apps introduced in future". Results showed the good reliability of this construct as 0.902 composite reliability.

\section{Results and analysis}

Questionnaire of this paper also acquired respondent's information, which wa also analyzed and showed that total 415 respondentnts filled the survey among which $229(55.2 \%)$ are male and $186(44.8 \%)$ are female tourists which is making it obvious that mostly tourists are male who visit Bang Nam Pheung Market. As well, mainstream of tourists was aged less than 25 years (128 respondents $-30.8 \%$ ), Tourists having age of 25 
to 35 years old $(176-42.4 \%)$, tourists from age group of 35 to 45 Years $(95-22.9 \%)$ and aging above 45 years $(16-3.9 \%)$ which indicates that young tourists were leading the sample. Almost, $15.7 \%$ of the respondents have travelling experience of Less than 2 Years, $42.2 \%$ have experience of 2 to 5 Years, $32.8 \%$ were experienced for 5 to 8 years and $9.4 \%$ tourists had more than 8 years' experience.

Table 2: Descriptive Statistics

\begin{tabular}{llllllll}
\hline & $\mathrm{N}$ & \multicolumn{3}{c}{ Minimum } & Maximum & Mean & \multicolumn{3}{l}{ Std. Deviation Skewness } \\
\cline { 2 - 7 } & Statistic & Statistic & Statistic & Statistic & Statistic & Statistic & Std. Error \\
\hline ConIntUMA & 415 & 1.00 & 5.00 & 3.3060 & .97540 & -.360 & .120 \\
ITKnowled & 415 & 1.00 & 5.00 & 3.5416 & 1.15100 & -.575 & .120 \\
PersonInn & 415 & 1.00 & 5.00 & 3.2129 & 1.20383 & -.275 & .120 \\
Awerness & 415 & 1.00 & 5.00 & 3.5488 & 1.13300 & -.463 & .120 \\
DesInfRisk & 415 & 1.00 & 5.00 & 3.3775 & 1.13922 & -.470 & .120 \\
Valid & $\mathrm{N} 415$ & & & & & & \\
(listwise) & & & & & & & \\
\hline
\end{tabular}

Descriptive analysis computes Descriptive Statistics for proposed variables to summarize the comprehensive data of sample by quantifying the basic characteristics. $\mathrm{N}$ (number of observation survey) is four hundred and fifteen. No outlier and variance among sample was found in test with having the threshold values for minimum and maximum. Mean values for continuous intention to use mobile application is 3.3060, IT Knowledge $=3.5416$, personal innovation $=$ 3.2129 , awareness $=3.5488$ and destination infrastructure risk $=3.3775$ to 3.5 indicative of agreeableness. The skewness measures test normality of the data. This table also indicate skewness that lie between -1 and +1

Table 3: KMO and Bartlett's Test

\begin{tabular}{lll}
\hline Kaiser-Meyer-Olkin Measure of Sampling Adequacy. & .924 \\
Bartlett's Test of Sphericity & Approx. Chi-Square & 7538.959 \\
& df & 153 \\
& Sig. & .000 \\
\hline
\end{tabular}

KMO and Bartlett's Test is steered to sum competency and suitability of sample size. The results showed Kaiser-Meyer-Olkin Measure of Sampling Adequacy as .924 which is above 0.7 and almost is 1 favoring data validity. Bartlett's
Test of Sphericity has Approx. Chi-Square of 7538.959, degree of freedom of 153.000 significances which correspondingly confirms adequacy of sample.

Table 4: Rotated Component Matrix ${ }^{a}$

\begin{tabular}{lccccc}
\hline & \multicolumn{5}{c}{ Component } \\
\cline { 2 - 5 } & 1 & 2 & 3 & 4 & 5 \\
\hline CI1 & & .836 & & \\
CI2 & & .902 & & \\
CI3 & & .860 & & \\
IT1 & .849 & & &
\end{tabular}




$\begin{array}{ll}\text { IT2 } & .850 \\ \text { IT3 } & .823 \\ \text { IT4 } & .882 \\ \text { IT5 } & .910 \\ \text { IT6 } & .894\end{array}$

PI1 $\quad .831$

$\mathrm{PI} 2 \quad .866$

$\mathrm{PI} 3 \quad .851$

AW1 $\quad .851$

AW2 $\quad .840$

AW3 $\quad .863$

$\begin{array}{ll}\text { DI1 } & .803\end{array}$

$\begin{array}{ll}\text { DI2 } & .808\end{array}$

DI3 $\quad .845$

The above table of Rotated Component Matrix displays the factor loading to degree the correspondence of variables' items. Each item is correlated because they hold factor loading which is exceeding 0.7 as factor loading of 18 items fluctuates between .803 and .910 fulfilling the criteria which is a evidencing high level of correlation of items. Thus, no loading error is exposed.

Table 5: Convergent and Discriminant Validity

\begin{tabular}{lllllllll}
\hline & CR & AVE & MSV & IT & PI & AW & DI & CI \\
\hline IT & 0.927 & 0.832 & 0.278 & 0.912 & & & & \\
PI & 0.927 & 0.792 & 0.497 & 0.484 & 0.890 & & & \\
AW & 0.904 & 0.759 & 0.255 & 0.500 & 0.306 & 0.871 & & \\
DI & 0.932 & 0.820 & 0.497 & 0.527 & 0.705 & 0.474 & 0.906 & \\
CI & 0.902 & 0.754 & 0.255 & 0.445 & 0.307 & 0.505 & 0.388 & 0.868
\end{tabular}

It is determined from the outcomes of convergent validity that destination infrastructure risk holds high composite reliability 0.932 confirming high level of reliability. While continuous intention to use mobile application has lowest composite reliability which is 0.902 . The lowest AVE is also estimated for continuous intention to use mobile application is 0.754 . As the values are between 0.5 and 0.7 which yields satisfactory Convergent validity. The discriminant validity outcomes are illustrated in diagonal arrangement indicating discriminant validity as MSV $<$ AVE.

Table 6: Model Fit Indices

\begin{tabular}{llllll}
\hline CFA Indicators & CMIN/DF & GFI & IFI & CFI & RMSEA \\
\hline Threshold Value & $\leq 3$ & $\geq 0.80$ & $\geq 0.90$ & $\geq 0.90$ & $\leq 0.08$ \\
Observed Value & 2.428 & 0.921 & 0.976 & 0.976 & 0.059 \\
\hline
\end{tabular}

The model fitness is assessed by valuing (CMIN) 2.428, (CFI) 0.976, (IFI) 0.976, (GFI) 0.921 and (RMSEA) values 0.059 . As table 5 shows that values are constant to threshold values. It can be openly resoluted the model is acknowledged to be fit. 
Figure 3: CFA

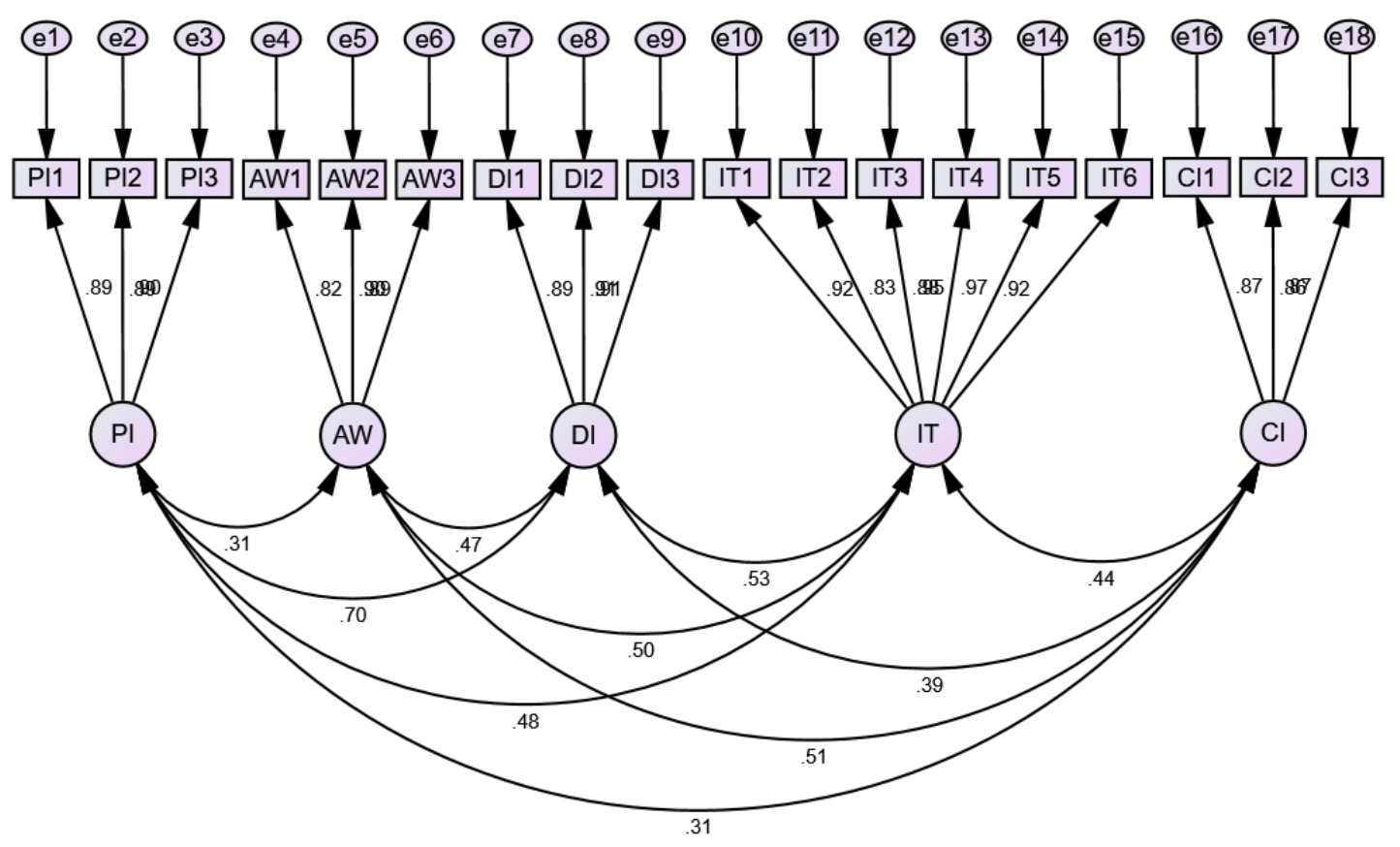

Table 7: Structural Equation Modeling

\begin{tabular}{lllllll}
\hline & & & Estimate & S.E. & C.R. & P \\
\hline ConIntUMA & $<---$ & PersonInn & .005 & .042 & .096 & .924 \\
ConIntUMA & $<---$ & Awerness & .423 & .038 & 9.623 & $* * *$ \\
ConIntUMA & $<---$ & DesInfRisk & .267 & .048 & 4.813 & $* * *$ \\
& & & Estimate & S.E. & C.R. & P \\
ZConIntUMA & $<---$ & ITxPI_Int1 & .116 & .038 & 2.840 & .005 \\
ZConIntUMA & $<---$ & ITxAW_Int2 & .100 & .036 & 2.452 & .014 \\
ZConIntUMA & $<---$ & ITxDI_Int3 & -.137 & .036 & -3.355 & $* * *$ \\
\hline
\end{tabular}

Structural Equation Model portrayed that enhancing personal innovation by a unit cause direct increase of only $0.5 \%$ in Continuous intention to use mobile-apps. However, a change in awareness accounted for increment of $42.3 \%$ in Continuous intention to use mobile-apps. In addition, rising Destination-infrastructure risk bring $26.7 \%$ upgrade in intention to use mobile applications. SO these variables have significant relationship and are approved by SEM. Moreover, IT knowledge significantly mediates personal innovation and intention to use mobile by $11.6 \%$ and intermediates awareness and intention to use mobile-apps. On other hand, IT knowledge has negative impact on destination-infrastructure risk and continuous intention to use because single unit change in IT knowledge cause decrease of $13.7 \%$ intention to use mobile applications so these hypothesis is rejected (Hameed, Basheer, Iqbal, Anwar, \& Ahmad, 2018; Hassan, Hameed, Basheer, \& Ali, 2020; Olajide, Ayodeji, \& Olusade, 2020; Olarewaju, 2019; Omotayo, 2019; Onyele \& Ikwuagwu, 2020; Opoku, Okyireh, \& Kissi, 2020; Ul-Hameed, Mohammad, \& Shahar, 2018; Zahra, Hameed, Fiaz, \& Basheer, 2019) 
Figure 4: SEM
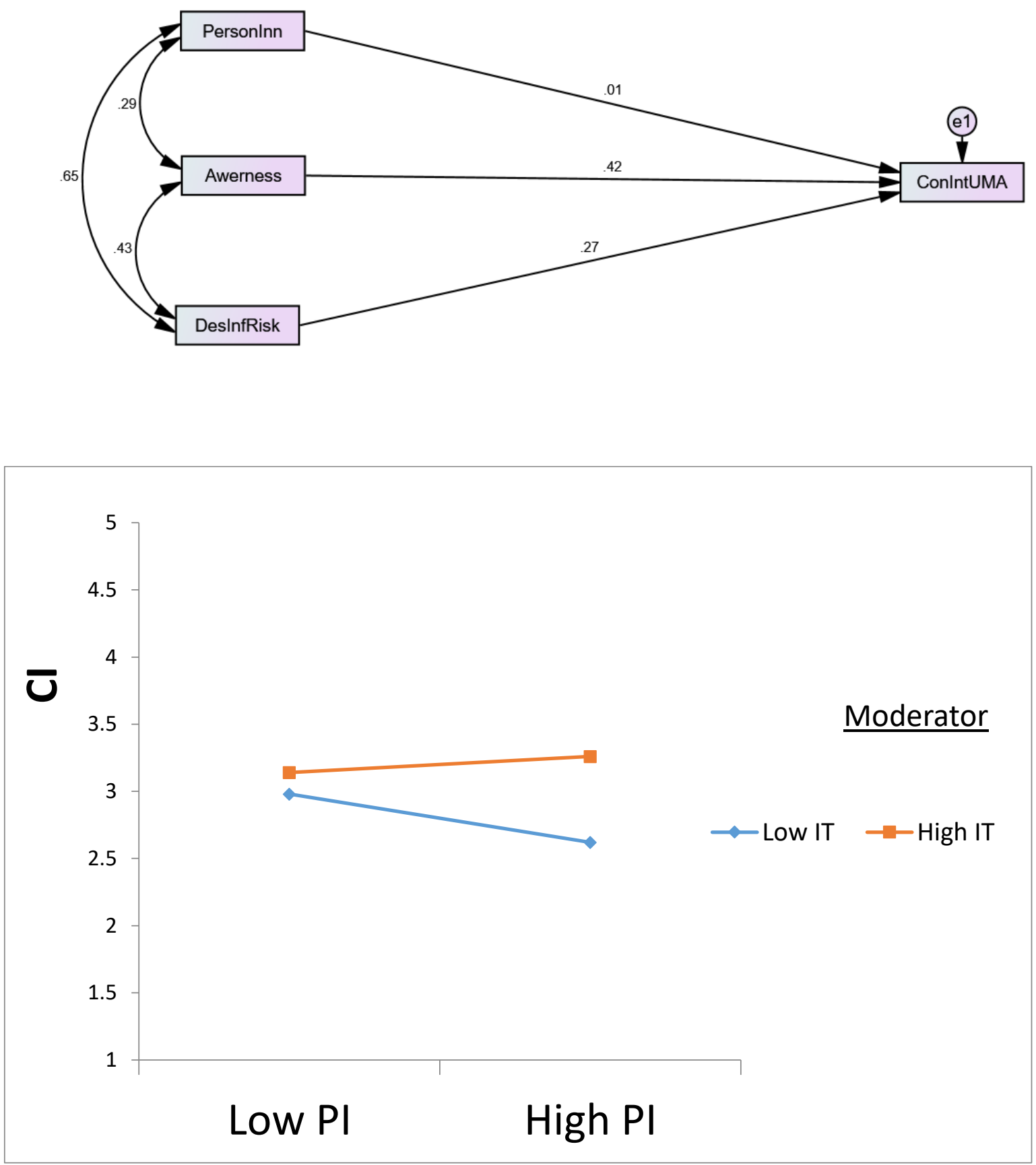

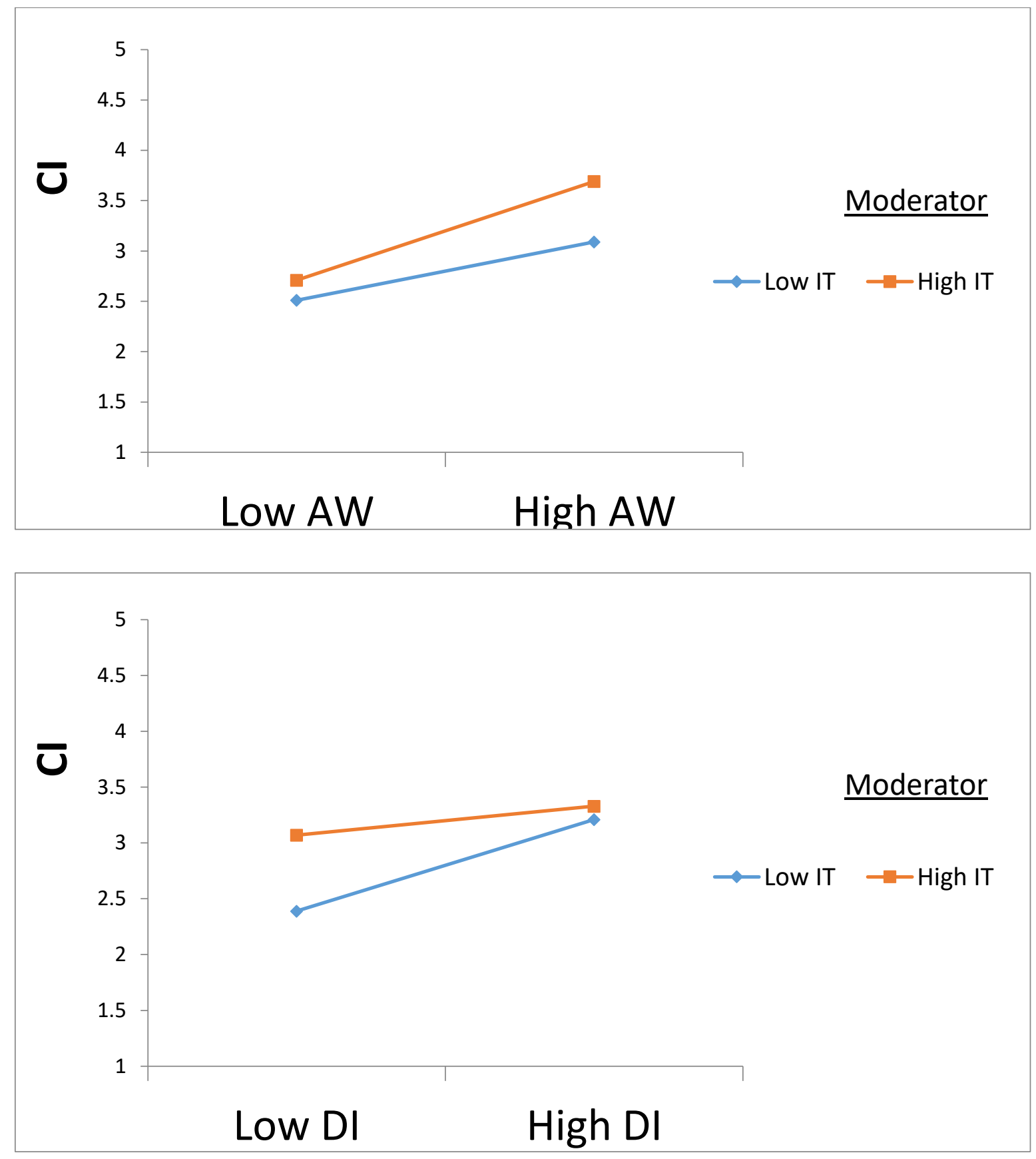

\section{Discussion and conclusion}

The rapid use of mobile technology is indispensable which has also considerably changed tourism and now tourists and tourism related entities seek to use mobile application to enhance tourism. The study examined the intention of tourists to use mobile applications in travelling and different factors that influence the intention. It is an empirical study and to statistically prove the research model by hypothesizing their relationships into six hypotheses. The relationship between personal innovation and continuous intention to use M- apps was checked by developing a hypothesis $\mathrm{H} 1$ which was preceding significant relationship between personal innovation and continuous intention to use it was confirmed that personal innovation evoke tourist intention to mobile apps which is align with C.-Y. Wang, Chou, and Chang (2010) findings so it is suggested that person inclination towards using new technology significantly shape intention to use mobile applications. Similarly, the awareness significantly upsurges continuous intention to use M-apps (H2) it was inferred from the results it is supported by Dayour, Adongo, and Agyeiwaah 
(2020) which stated that user's knowledge and information of mobile application influence intention to use mobile-applications. The relationship between Destination-infrastructure risk and continuous intention to use mobile applications (H3) was found to be significant as increase in risk enhance continuous intention to use mobile application by tourists, it reinforced by (Oliveira, Thomas, Baptista, \& Campos, 2016). This paper also explored the moderating effect of IT knowledge on intention to use mobile applications. H4 which is showing significant moderating effect of IT- knowledge between personal innovation and continuous attention to used mobile applications. Results approved this hypothesis as IT knowledge enhance personal innovation that how to operate technology which stimulate intention to use M-apps (Huang et al., 2016). The H5 anticipated that IT knowledge favorably moderates the relationship between awareness and continuous intention to use Mapps. The findings supported this variable by showing positive link between these variables which means It knowledge enhance awareness with new technology and instigate intention to use technology. H6 proposed that IT knowledge significantly moderates the relationship between destination infrastructure risk and continuous intention to use Mob-apps which turned out to be insignificant. It was pointed that IT knowledge does not strengthen continuous intention to use mobile due to risk of destination infrastructure.

Even the increased usage of mobile-based application and services has grabbed considerable attention in past however, the factor behind this continuous usage is not comprehensively explored and there are number of gaps that call for attention especially in tourism industry. This study is one of the primary empirical study in Thailand's province Samut Parkan to identify the dynamics that influence continuous intention to use mobileapplication and similar services in travelling. The study confirmed the significant relationship between Personal innovation, awareness and continuous intention to use mobile applications whereas it detected inverse relationship between Destination-infrastructure risk and intention to use mob-apps. Which provided direction to tourism industry policy makers and government for developing effective infrastructure to support mobile-application integration. The study deemed to expand literature on mobile-application implementation in tourism in relation to personal innovation and other drivers. It recommends mobile app developers to develop user-friendly and easy tasking application to encourage tourists to use mobile-applications.

\section{REFERENCES}

[1] Afolabi, O. O., Adeshola, I., Ozturen, A., \& Ilkan, M. (2020). THE INFLUENCE OF CONTEXT ON PRIVACY CONCERN IN SMART TOURISM DESTINATIONS.

PEOPLE: International Journal of Social Sciences, 6(1).

[2] Al-Emran, M., Mezhuyev, V., \& Kamaludin, A. (2018). Technology Acceptance Model in M-learning context: A systematic review. Computers \& Education, 125, 389-412.

[3] Ardito, L., \& Petruzzelli, A. M. (2017). Breadth of external knowledge sourcing and product innovation: the moderating role of strategic human resource practices. European Management Journal, 35(2), 261-272.

[4] Canbek, N. G., \& Mutlu, M. E. (2016). On the track of artificial intelligence: Learning with intelligent personal assistants. Journal of Human Sciences, 13(1), 592-601.

[5] Carvajal-Trujillo, E., Molinillo, S., \& Liébana-Cabanillas, F. (2020). Determinants and risks of intentions to use mobile applications in museums: an application of fsQCA. Current Issues in Tourism, 1-20.

[6] Chao, C.-M. (2019). Factors determining the behavioral intention to use mobile learning: An application and extension of the UTAUT model. Frontiers in psychology, 10, 1652.

[7] Chaurasia, S. S., Verma, S., \& Singh, V. (2019). Exploring the intention to use M- 
payment in India. Transforming Government: People, Process and Policy.

[8] Chen, C.-C., \& Tsai, J.-L. (2019). Determinants of behavioral intention to use the Personalized Location-based Mobile Tourism Application: An empirical study by integrating TAM with ISSM. Future Generation Computer Systems, 96, 628-638.

[9] Christian, K., Pierce, J. S., Robson, C. M., \& Schoudt, J. T. (2016). Location-based mobile application and service selection: Google Patents.

[10] Chuentako, Y. (2019). GUIDELINES FOR THE DEVELOPMENT OF COMMUNITYBASED TOURISM ACTIVITIES: A CASE STUDY OF BANG KACHAO, PHRA PRADAENG, SAMUT PRAKARN, THAILAND. Paper presented at the INTERNATIONAL ACADEMIC MULTIDISCIPLINARY RESEARCH CONFERENCE IN VIENNA 2019.

[11] Dayour, F., Adongo, C. A., \& Agyeiwaah, E. (2020). Continuous intention to use mobile money (MM) services: Driving factors among small and medium-sized tourism and hospitality enterprises (SMTHEs). Africa Journal of Management, 1-30.

[12] Dayour, F., Park, S., \& Kimbu, A. N. (2019). Backpackers' perceived risks towards smartphone usage and risk reduction strategies: A mixed methods study. Tourism Management, 72, 52-68.

[13] Desai, N. S. (2016). Mobile cloud computing in business. International Journal of Information, 6(1/2).

[14] Dzogbenuku， R. K., Amoako, G. K., \& Kumi, D. K. (2019). Social media and student performance: the moderating role of ICT knowledge. Journal of Information, Communication and Ethics in Society.

[15] Gerrard, P., Cunningham, J. B., \& Devlin, J. F. (2006). Why consumers are not using internet banking: a qualitative study. Journal of services Marketing, 20(3), 160-168.
[16] Hameed, W. U., Basheer, M. F., Iqbal, J., Anwar, A., \& Ahmad, H. K. (2018). Determinants of Firm's open innovation performance and the role of $\mathrm{R} \& \mathrm{D}$ department: an empirical evidence from Malaysian SME's. Journal of Global Entrepreneurship Research, 8(1), 29.

[17] Hassan, S. G., Hameed, W. U., Basheer, M. F., \& Ali, J. (2020). ZAKAT COMPLIANCE INTENTION AMONG SELF-EMPLOYED PEOPLE: EVIDENCE FROM PUNJAB, PAKISTAN. AL-ADWAH, 34(2), 80-96.

[18] Huang, S., Afsharifar, A., \& Veen, R. v. d. (2016). Examining the moderating role of prior knowledge in the relationship between destination experiences and tourist satisfaction. Journal of Vacation Marketing, 22(4), 320-334.

[19] Jiang, Z., Hu, X., Wang, Z., \& Jiang, X. (2019). Knowledge hiding as a barrier to thriving: The mediating role of psychological safety and moderating role of organizational cynicism. Journal of Organizational Behavior, 40(7), 800-818.

[20] Mao, H., Liu, S., Zhang, J., \& Deng, Z. (2016). Information technology resource, knowledge management capability, and competitive advantage: The moderating role of resource commitment. International Journal of Information Management, 36(6), 1062-1074.

[21] Mushwana, J. T., \& Maziriri, E. (2017). Antecedents that influence Johannesburg customers' intention to use Transportation Network Companies (TNCs): perspectives on the Uber mobile application. Master of Business Administration. Regenesys Business School, Sandton. South Africa.

[22] Natarajan, T., Balasubramanian, S. A., \& Kasilingam, D. L. (2017). Understanding the intention to use mobile shopping applications and its influence on price sensitivity. Journal of Retailing and Consumer Services, 37, 822. 
[23] Nzeribe, A. (2019). Appointment of Directors and Performance of Deposit Money Banks in Sub Saharan Africa: Do We Need More Executive or Non-Executive Directors? Journal of Empirical Studies, 6(1), 1-18. doi: 10.18488/journal.66.2019.61.1.18

[24] Ofino, E. E., \& Orisadare, M. A. (2020). Analysis of Causal Nexus between Defense Spending and Economic Growth in Nigeria: A Toda-Yamamoto Approach. The Economics and Finance Letters, 7(1), 76-84. doi: 10.18488/journal.29.2020.71.76.84

[25] Ogunjimi, J. (2020). Exchange Rate Dynamics and Sectoral Output in Nigeria: A Symmetric and Asymmetric Approach. American Journal of Social Sciences and Humanities, 5(1), 178-193. doi: 10.20448/801.51.178.193.

[26] Okulich-Kazarin, V., Zhurba, M., Pagava, O., Kalko, I., \& Serbin, I. (2019). Lecture Method Preferences, Auditory or Visual, of Ukrainian Consumers of Educational Services: A Statistical Analysis. International Journal of Education and Practice, 7(2), 5465. doi: 10.18488/journal.61.2019.72.54.65

[27] Olajide, O. A., Ayodeji, O. C., \& Olusade, A. P. (2020). Employee Relations: Influence of Communication Openness on Employee Job Satisfaction (A Study of Secondary School Teachers in Kogi State, Nigeria). Global Journal of Social Sciences Studies, 6(1), 3950. doi: 10.20448/807.6.1.39.50

[28] Olarewaju, F. O. (2019). Determinants of Public Sector Corruption in Nigeria. International Journal of Public Policy and Administration Research, 6(1), 1-11. doi: 10.18488/journal.74.2019.61.1.11.

[29] Oliveira, T., Thomas, M., Baptista, G., \& Campos, F. (2016). Mobile payment: Understanding the determinants of customer adoption and intention to recommend the technology. Computers in Human Behavior, 61, 404-414.

[30] Omotayo, E. A. (2019). The Dynamic Interplay of the Global and Local
Environments: A Study of Chimamanda Adichie's Americanah. International Journal of English Language and Literature Studies, $8(1), \quad 19-27 . \quad$ doi: 10.18488/journal.23.2019.81.19.27

[31] Onyele, K., \& Ikwuagwu, E. (2020). The Globalization Wave and Stock Market Return in Africa. International Journal of Economics, Business and Management Studies, $7(1), \quad 80-94 . \quad$ doi: 10.20448/802.71.80.94

[32] Opoku, D., Okyireh, R. O., \& Kissi, P. S. (2020). Consumer Intention towards the Use of Bible Application. American Journal of Education and Learning, 5(1), 72-86. doi: 10.20448/804.5.1.72.86.

[33] Palos-Sánchez, P., Saura, J. R., \& ÁlvarezGarcía, J. (2019). Innovation and creativity in the mobile applications industry: a case study of mobile health applications (e-Health Apps) Cultural and Creative Industries (pp. 121135): Springer.

[34] Papa, A., Dezi, L., Gregori, G. L., Mueller, J., \& Miglietta, N. (2018). Improving innovation performance through knowledge acquisition: the moderating role of employee retention and human resource management practices. Journal of Knowledge Management.

[35] Pittino, D., Martínez, A. B., Chirico, F., \& Galván, R. S. (2018). Psychological ownership, knowledge sharing and entrepreneurial orientation in family firms: The moderating role of governance heterogeneity. Journal of Business Research, 84, 312-326.

[36] Pongajarn, C., van der Duim, R., \& Peters, K. (2018). Floating markets in Thailand: same, same, but different. Journal of Tourism and Cultural Change, 16(2), 109-122.

[37] Rogers, E. (2003). Diffusion of innovations, 5th edn Tampa. FL: Free Press.[Google Scholar].

[38] Scherer, R., Siddiq, F., \& Tondeur, J. (2019). The technology acceptance model (TAM): A meta-analytic structural equation modeling 
approach to explaining teachers' adoption of digital technology in education. Computers \& Education, 128, 13-35.

[39] Sezgin, E., Özkan-Yildirim, S., \& Yildirim, S. (2017). Investigation of physicians' awareness and use of mHealth apps: A mixed method study. Health Policy and Technology, 6(3), 251-267.

[40] Tarute, A., Nikou, S., \& Gatautis, R. (2017). Mobile application driven consumer engagement. Telematics and Informatics, 34(4), 145-156.

[41] Torous, J., \& Roberts, L. W. (2017). Needed innovation in digital health and smartphone applications for mental health: transparency and trust. JAMA psychiatry, 74(5), 437-438.

[42] Ul-Hameed, W., Mohammad, H., \& Shahar, H. (2018). Microfinance institute's nonfinancial services and women-empowerment: The role of vulnerability. Management Science Letters, 8(10), 1103-1116.

[43] Venkatesh, V., Thong, J. Y., \& Xu, X. (2012). Consumer acceptance and use of information technology: extending the unified theory of acceptance and use of technology. MIS quarterly, 157-178.

[44] Wang, C.-Y., Chou, S.-C. T., \& Chang, H.-C. (2010). Exploring An Individual's Intention to Use Blogs: The Roles of Social, Motivational and Individual Factors. Paper presented at the PACIS.

[45] Wang, N., Sun, Y., Shen, X.-L., \& Zhang, X. (2018). A value-justice model of knowledge integration in wikis: The moderating role of knowledge equivocality. International journal of information management, 43, 6475.

[46] Wang, Y., Wang, S., Wang, J., Wei, J., \& Wang, C. (2018). An empirical study of consumers' intention to use ride-sharing services: using an extended technology acceptance model. Transportation, 1-19.
[47] Wang, Z., \& Wang, N. (2012). Knowledge sharing, innovation and firm performance. Expert systems with applications, 39(10), 8899-8908.

[48] Wu, B., \& Chen, X. (2017). Continuance intention to use MOOCs: Integrating the technology acceptance model (TAM) and task technology fit (TTF) model. Computers in Human Behavior, 67, 221-232.

[49] Zahra, M., Hameed, W. U., Fiaz, M., \& Basheer, M. F. (2019). Information Technology Capability a Tool to Expedite Higher Organizational Performance. UCP Management Review (UCPMR), 3(1), 94112. doi: http://dx.doi.org/10.2139/ssrn.1912358 